\title{
Role of conflict in shaping fertility preferences in Rwanda
}

\author{
Pierre Claver Rutayisire ${ }^{1}$ \\ Applied Statistics Department, National University of Rwanda, Rwanda
}

Annelet Broekhuis

International Development Studies Department, Utrecht University, Utrecht, The Netherlands.

Pieter Hooimeijer

Human Geography and Regional Planning Department, Utrecht University, Utrecht, The Netherlands.

\begin{abstract}
Conflicts affect the social and economic conditions that could account for the stall in fertility decline in sub-Saharan Africa. In Rwanda the total fertility rate decreased very rapidly to 6.1 in the eighties but stalled at that level in the nineties. Part of the stall can be attributed to a lack of fertility control, but the question is whether social upheaval also affects fertility preferences. We identify three mechanisms through which the Rwanda conflict has led to a preference for larger families: mortality experience, modernization, the attitudes of third parties.
\end{abstract}

Using data from DHS, we tested the contribution of these mechanisms to the preference for small, medium or large families. With the exception of sibling mortality, there is a strong impact by these mechanisms on the preference for large families, yet they do not fully account for the shifts in preferences over the years.

\section{Résumé}

Les conflits exercent un impact sur les facteurs socio-économiques qui à leur tour pourraient expliquer le ralentissement de la baisse de la fécondité en Afrique sub-saharienne. Le Rwanda, où le taux de fécondité a diminué très rapidement à 6.1 des années quatre-vingt, mais a stagné à ce niveau dans les années quatre-vingt-dix. Une partie de cette stagnation peut être attribuée à un manque de maîtrise de la fécondité, mais la question est de savoir si la guerre et le génocide au Rwanda ont affecté également les préférences de fécondité. Nous avons identifié trois mécanismes par lesquels les conflits peuvent conduire à une préférence pour les familles nombreuses: l'expérience de la mortalité, la modernisation, l'attitude des tiers.

Utilisant les données des EDS, nous avons testé la contribution de ces mécanismes à la préférence de la taille de la famille. À l'exception de la mortalité frères et sœurs, il y a un fort impact de ces mécanismes sur la préférence pour les familles larges, mais elles ne tiennent pas pleinement compte des changements dans les préférences au fil des années.

\section{Introduction}

The second phase of the demographic transition (DT) is the period in which fertility declines rapidly and ends when the total fertility rate reaches replacement level. Most countries in the world have gone through this phase and many, like China, actually have below replacement fertility. Sub-Saharan Africa is the only continent where the DT develops differently. In eight countries the fertility decline stalled at the early phase of the transition in the nineties of the previous century (Shapiro \& Gebreselassie 2008). Various explanations have been put forward for this phenomenon: high levels of infant and child mortality, economic stagnation, deterioration of reproductive health services, and lack of educational expansion (Bongaarts 2007, Schoumaker 2009). Some literature points to the effects of severe disruptive events like natural disasters and civil wars on these social and economic conditions that may account for the stall in fertility decline. For Rwanda this

I. Corresponding author contacts: Pierre Claver Rutayisire, Applied Statistics Department, National University of Rwanda, Rwanda. Emails: crutayisire@nur.ac.rw, rutayisirepc@gmail.com, Phone: +250 252 530I22, Fax:+ 250252530121 
approach seems to be appropriate. The total fertility rate decreased very rapidly in the eighties (from 8.5 in 1983 to 6.2 in 1992) but stalled at that level in the nineties (6.I in 2005). Recent data show that the demographic transition might have resumed its course recently (5.5 in 2008 and 4.6 in 2010).

In a previous paper we described how this stall in fertility decline coincided with changes in mortality experience, marriage patterns and discontinuation of family planning programs during the disruptive events in the early nineties (civil war, genocide, massive population movements). It is clear that the high fertility is at least partly due to a lack of fertility control. The actual use of modern contraceptive devices decreased after 1992 and the levels of unmet needs for reproductive health services increased. It is less clear to what extent higher fertility preferences play a role as well. The aim of this contribution is to isolate the role of fertility preferences by analyzing the shifts in desired family size in the period 1992-2008. We will indentify various mechanisms that could account for the change in the preference for small, medium and large family sizes in Rwanda.

\section{Theoretical background and hypotheses}

Desired family size or ideal number of children can be used an as important indicator of fertility preferences (De Silva 199I; Bankole and Westoff 1998). The more often cited determinants of desired family size are grouped into demographic factors such as age at marriage, mortality experience or gender preference, as well as socio-economic factors like level of education, current or childhood place of residence. This paper will take up these issues by grouping them in three main mechanisms: mortality experience, modernization process and the attitudes or influence of third parties.

\section{The mortality experience mechanism}

With the genocide in which 800000 people lost their lives, the decreasing level of mortality at the end of the 1980s in Rwanda increased in the 1990s and remained persistently high during the last years of the decade. (RDHS,2000; Housing and Population Census, 2002). Rathavuth (2009) describes the trends of neonatal, infant and under-five mortality to show how the mortality was high between 1995 and 2000.

A reconstruction of mortality levels by Garenne and Gakusi (2005) displays mortality increase since the beginning of the civil war, with a peak in 1994 due to genocide and a rise again in 1998 probably to the hardship of life due to return migration. Although the mortality reached all the strata of the population, Schindler and Brück (20II) relate the death of siblings, considered as a strong indicator of exposure to the genocide, with fertility, but only in the short term.

The early contributions on the decline in mortality and fertility from Frank Notestein (1953) saw societal modernization as the dominant cause. However, as early as 1963 Kingsley Davis stated the improved survival to be the central cause. An abundance of empirical evidence on the relationship between mortality and fertility has been gathered since. LeGrand et al. (2003) distinguish three pathways by which women or couples are going from child mortality to fertility: physiological, replacement and insurance (or holding) mechanisms. The first two mechanisms deal with individual (conscious or not) response by the woman who has lost her child. The proper way to study that is to consider the birth intervals and the desire to have an additional child. The concern in this paper is the third mechanism which is more focused on people's perceptions and understandings and on reconciling the desired number of children with their risks of dying.

In other words, the insurance hypothesis implies that the fear of losing children influences the ideal number of births. In countries like Rwanda this hypothesis can be extended to the loss of siblings, because this loss could contribute to the perception of the risk of losing one's own children. Siblings, just like adult children, are an important part of the social support system in hard times. The high prevalence of deaths in the period 1992-1995 might account for the peak in fertility preferences in the years after this period.

\section{The modernisation mechanism}

Without going into detailed arguments on the modernization theory our analysis refers to the modernisation mechanism in two ways. The 
first is to relate it with the role of women's education. The relation between women's education and the family size has been analyzed in various ways. These include the direct and indirect effect of women's education on actual family size (Janowitz, 1976; McCarthy and Oni, 1987; Jejeebhoy, 1995), the interrelation between woman's education, child survival and family size desires (Jejeebhoy, 1995) and the expected longer duration of education for the children that reduces the number women want (McCarthy and Oni, 1987). There is some evidence that the real change in women's preferences occurs among those who reached secondary or higher levels of education (Uche and Isugo, 1994).

Furthermore, this relationship changes over time and depends on contextual factors being stronger or remaining the same in countries at early stages of fertility transition rather than being reduced, except for the more developed countries, characterized by a consistent fertility decline (Jejeebhoy, 1995).

Based on this evidence from the literature, women's level of education will be included in our analyses in order to investigate how the fertility preferences can change with or remain constant without further educational expansion.

Women's occupations as well as a husband's or partner's occupation could be used as proxy of socio-economic factors related to the ideal number of children. For women the occupation does not only constitute an indicator of household wealth, but also illustrates her autonomy in decision making. The type of occupation could also lead to a different valuation of children as either a cost or a benefit in terms of an extra hand on the farm.

The education and occupation of the husband would add to the wealth effects and together they are expected to lead to a desire for smaller families, because an increase in wealth shifts the quantity/quality trade-off of children, and because more educated couples will easily discuss family planning and will be open to the use of contraceptive methods (Cochrane 1990, Ezeh et al. 1993).

The second factor related to the modernization mechanism is urbanization which links the childhood and current place of residence. It has been documented that women living in rural areas have distinctly higher fertility preferences than urban women, even after accounting for the difference in occupation and educational level (Knodel et al. 1996). The additional impact of place of residence on fertility intentions could be due to socio-cultural factors linked to modernization and to different urban and rural labour market conditions.

This raises the question whether migrants from the countryside bring to the city more traditional values on fertility or assimilate more modern views either before or after the move to the city. This is known as the adaptation hypothesis which relies on the idea that fertility behaviour of migrants will change from childhood dominant behaviour to resemble the fertility preferences dominant at the destination (Kulu, 2005). For rapidly urbanizing countries like Rwanda this is an important issue, and we will categorize women according to their place of residence at the moment of interview and to where they spent the childhood in our models.

\section{Attitudes of third parties}

The attitudes of the husband or partner as well as other community members, like parents or mothers in law, are the third mechanism that may account for the change in fertility preferences in developing countries. Third parties might have an effect on the reported fertility preferences of women as they are affected by the society, which is a patriarchy in most of the cases in sub-Saharan Africa. It is therefore unlikely that the fertility preference could be explained by individual characteristics only, even for educated and employed women as the role of the male is still preponderant (Woldemicael, 2007). The complication of including in research and reproductive health programs direct measurements of women's autonomy has encouraged scholars to expand their analysis on other variables like religion, access to media and partner's individual characteristics such as approval of family planning or even discussion about it. As it is a multi-dimensional concept it has been defined in relation with men or other women in terms of culture, religious beliefs, traditions and economic environments and sometimes as women's status. Therefore the concept is difficult to capture with a single measurement (Goni and Saito, 2009). In this paper, we expect the 
attitudinal variables related to third parties, such as approval of family planning or its discussion among partners, to be a way of regulating the future fertility by reducing the fertility preferences. Joint decision making may bring women closer to expected results than individual characteristics.

\section{Some control variables}

The ideal number of children could also be related to the age of women as their reproductive capacity declines dramatically after the fourth decade of life. One could consider a positive relationship between the desire for larger families and age in two ways. The first mechanism could be that young women cope better with the modern reproductive means than their older sisters who may replicate more traditional reproductive norms. The second is the rationalisation of the actual number of children into a preferred number.

Based on the fact that in Rwanda almost all the births occur in marriage, we expect the fertility preference to be higher for married women than those formerly married or those who declare themselves to be single.

There is evidence in the literature that marriage formation slows down in a period of crisis and recovers directly after the disrupting event (Nobles \& Buttenheim, 2006). Assuming conscious fertility control within marriage, women or couples will delay births voluntarily and those who are not married will delay the formation of a stable partnership and will favour smaller family as a consequence of economic hardships (Palloni et al. 1996; Lindstrom et al. 1999).

The central hypothesis of this paper is that the increase in desired family size in Rwanda in the aftermath of the 1994 genocide can be attributed at least in part to a rise in mortality experience, both of children and siblings, but is also supported by the slowing down of the urbanization process and the fact that educational expansion came to a halt. However, these mechanisms may not fully account for the change in fertility preferences over the years. There might be an extra effect of the disrupting event itself on the mindset of women involved either through third party effects which favour more pro-natalist attitudes or because the loss of family through war brings about extra uncer- tainty in deciding on the ideal number of children.

\section{Data description and methods}

In his classical contribution Pullum (1983) described some characteristics to be considered when analyzing the desired family size in less developed countries. In the latter the ideal number of children can be illustrated a projected ideal (e.g. for one's daughter), as a personal ideal (what is best for one's family) or as a generalized ideal (what is best for the community or country). Even if it is measured as a personal ideal, more general considerations might come into play. The desired size will be more indicative of the mindset than a prediction of the actual fertility over the life course.

Depending on the level of autonomy of the woman in the country of survey, third parties might influences the response consciously (if present at the interview) or subconsciously, and the declared number would basically indicate the one with a relative convenience for the respondent.

As we are not using the desired family size as a predictor of future actual fertility, but are interested in whether personal and collective experience affects the mind-set when it comes to fertility preferences, these issues do not hamper our analyses but will be taken into account in defining the models and used in the interpretation of the results.

In this paper, we use the Rwanda Demographic Health Surveys (RDHS) of 1992, 2000, 2005 and the interim RDHS of 2008. The use of the latter instead of the 2010 RDHS was based on the different formulation of the variable on the urbanisation. In the four previous datasets this variable has three categories (Kigali, Small cities and Countryside) whereas in 2010 the variable been replaced by a categorisation of region (Kigali, South, West, North and East) instead of urbanisation. In addition to data on the birth histories of women, background characteristics of women aged 15 to 49 years old and their husband if any were collected at the moment of the survey.

The dependent variable used in this study is a question in the RDHS designed to measure the fertility preferences using the ideal number of children as stated by both women having chil- 
dren or not. The question in the RDHS is phrased as: "If you could go back to the time when you did not have any children and could choose exactly the number of children to have in your whole life, how many would that be? Or if you could have exactly the number of children you want, what would that be?" This variable has responses from zero children to twenty and more and one category of non-numeric responses. Women who stated that their ideal number of children is twenty or more as well as those who expressed it as a non-numerical answer (e.g. "it is God's will"), are taken together with women who declared a very high number of desired offspring.

There are two reasons to doubt that the dependent variable is of ratio level. The first reason is that the intervals between the numbers listed are not proportional. In a context where practically no one wants less than three children, one might wonder about the difference between one, two and three. At the other end of the distribution the difference between seven, eight, nine, or more might not be a deliberate choice, but triggered by the need to give a finite number. The second reason is the relative utility of any given number. One more or one less could be acceptable. We solved this by treating the ideal number of children as an ordinal variable, taking Zero-Three children as one category, Four and Five as separate categories and Six and over as a measure of wanting many children.

The explanatory factors as stated in the theoretical background are grouped into mortality experience, modernization process, and attitudes of third parties. The first independent variables are mortality of offspring and siblings' mortality, which are grouped into three categories each: no mortality experience, the respondent experienced one or two losses, and those who experienced the death of three or more.

$$
\operatorname{Ln}(\theta j)=\alpha j-\beta i X i
$$

Where $\mathrm{j}$ ranges from $\mathrm{I}$ to the number of categories minus one

And $(\mathrm{j})=$ probability $($ score $\mathrm{j}) /(\mathrm{I}$ - probability (score j))
The mortality of offspring is related to all children who died as stated by the respondents, whereas the death of siblings is associated with brothers and sisters of respondents who died in the period of the genocide (1993, 1994 and 1995). The second group of explanatory variables are education and urbanisation. Women's highest level of education is categorized as noneducated, incomplete primary, completed primary, incomplete secondary, secondary or plus. The migration history combines the actual place of residence with the childhood place of residence and is used to measure the extent to which the place where one's lives has impact on the fertility preference in terms of individual or collective choices. The third group is the approval of family planning by the partner and the discussion of family planning by the couple. In addition age or marital status are included as control variables. Women selected for the purpose of this study are aged from 20 years to 49 years old.

We used ordinal logistic regression to model the woman's ideal number of children because of the ordinal nature of the outcome variable, but also because it offers interesting analytic options such as going beyond simple significance testing, summarizing the association of interest of all levels of outcome and assessing confounding and interaction effects for all independent variables (Scott et al. 1997).

The ordinal logistic regression, often referred to as the proportional odds model (Norris et al. 2006), or cumulative logit, is an extension of the binary logistic regression and an appropriate method of analysis for grouped continuous response variable (Lall, $\mathrm{R}$. et al. 2002). This ordinal model consists of $n-I$ logit equations, assuming the odds of each equation to be proportional, also known as the parallel lines assumption. Its functional form is:
The ${ }_{j}$ 's is referred to as a threshold or intercept. Each category of the independent variables except the highest (here: reference category) has its own threshold. In our analysis, , = the 
log-odd of wanting three or less children, $2=$ the log-odd of wanting four or less and ${ }_{3}=$ the log-odd of wanting five or less. The rest want six or more children.

A positive parameter is subtracted from this threshold, indicating lower chances of wanting few children and higher chances of wanting more. The higher the parameter the more children women desire. As the model is proportional each logit has the same coefficient.

Allison (1999) concluded that this approach may be invalid and even misleading when comparing groups, as the dispersion in the response probabilities could not be uniform across groups, violating the assumption of parallel lines. The risks of violating this assumption are

$$
\operatorname{Logit}[P(Y \leq j x)]=\frac{\alpha j-\beta x}{\exp (y x)}
$$

With $y$ being a vector of parameter estimates referring to the scale model (Jansen $M$. et al. 2009). This shows that when $y=0$ the locationscale model is reduced to the cumulative logit model. The higher $y$, the larger is the dispersion for the groups defined by the explanatory variables and when it is lower than zero this means the groups defined by the explanatory variables are more homogeneous in terms of ideal number of children. reduced if the model is well specified and includes interaction effects to account for heterogeneity within groups (Williams 2009), but there is no guarantee that it captures unequal dispersion.

Therefore we use the heterogeneous choice models, also known as location-scale models. The location model gives the shift in the response probability to either right or left, while the scale model explicitly models the dispersion in the response probabilities (Jansen $M$. et al. 2009). This model offers, in addition to the shifts in the ideal number of children, more clarity about the heterogeneity within certain specified groups. The model is extended and redefined as follows:

\section{Results}

Four data sets (I992, 2000, 2005 and 2008) of women aged from 20 to 49 years old have been used for the analysis (Table I). Unfortunately no data were collected in 1996, which would have given information directly after the disruptive of the 1994 genocide. Collecting data was clearly not the first priority in the years after the traumatic event.

Graph 1: Relation between year of interview and ideal number of children

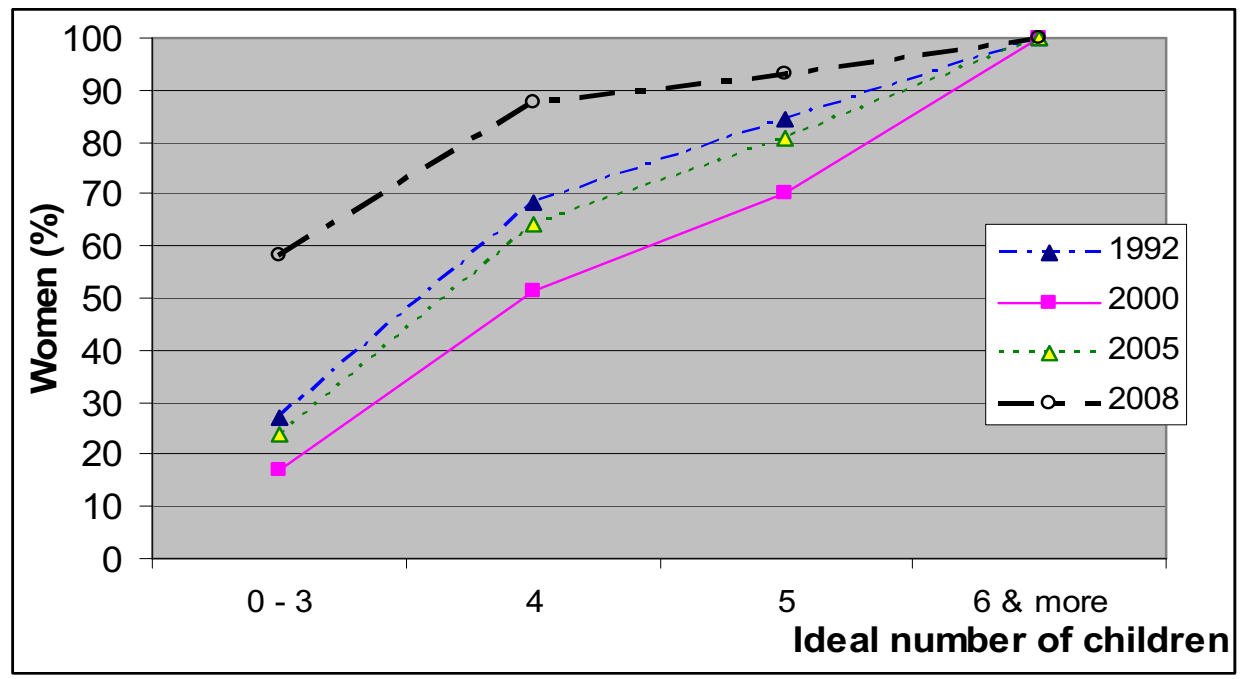


Table I Descriptive statistics by year of interview

\begin{tabular}{|c|c|c|c|c|}
\hline Variables & 1992 & 2000 & 2005 & 2008 \\
\hline \multicolumn{5}{|l|}{ Ideal number of children } \\
\hline $0-3$ & $26.7 \%$ & $17.5 \%$ & $23.1 \%$ & $54.2 \%$ \\
\hline 4 & $40.8 \%$ & $35.7 \%$ & $41.8 \%$ & $31.8 \%$ \\
\hline 5 & $15.6 \%$ & $17.7 \%$ & $15.3 \%$ & $6.1 \%$ \\
\hline $6+$ & $16.9 \%$ & $29.1 \%$ & $19.8 \%$ & $7.9 \%$ \\
\hline \multicolumn{5}{|c|}{ Mortality experience (Children) } \\
\hline 0 & $61.5 \%$ & $59.8 \%$ & $63.2 \%$ & $71.8 \%$ \\
\hline 1 & $19.6 \%$ & $20.7 \%$ & $19.5 \%$ & $16.3 \%$ \\
\hline 2 & $9.6 \%$ & $10.0 \%$ & $9.3 \%$ & $6.9 \%$ \\
\hline 3 & $4.8 \%$ & $5.2 \%$ & $4.3 \%$ & $3.0 \%$ \\
\hline $4+$ & $4.5 \%$ & $4.3 \%$ & $3.7 \%$ & $2.1 \%$ \\
\hline \multicolumn{5}{|l|}{ Level of education } \\
\hline No education & $40.4 \%$ & $32.2 \%$ & $27.3 \%$ & $23.9 \%$ \\
\hline Inc. primary & $42.2 \%$ & $36.0 \%$ & $49.5 \%$ & $45.0 \%$ \\
\hline Primary & $6.7 \%$ & $17.8 \%$ & $11.6 \%$ & $18.1 \%$ \\
\hline Inc. secondary & $8.9 \%$ & $10.0 \%$ & $7.7 \%$ & $7.2 \%$ \\
\hline Secondary & $1.3 \%$ & $3.1 \%$ & $2.9 \%$ & $4.1 \%$ \\
\hline Higher & $0.5 \%$ & $0.9 \%$ & $1.0 \%$ & $1.7 \%$ \\
\hline \multicolumn{5}{|l|}{ Type of place of residence } \\
\hline Countryside & $82.5 \%$ & $75.9 \%$ & $77.4 \%$ & $74.1 \%$ \\
\hline Small cities & $6.4 \%$ & $10.2 \%$ & $13.2 \%$ & $15.5 \%$ \\
\hline Kigali & $1 \mathrm{I} .1 \%$ & $13.9 \%$ & $9.4 \%$ & $10.4 \%$ \\
\hline \multicolumn{5}{|l|}{ Marital status } \\
\hline Never married & $16.5 \%$ & $15.7 \%$ & $20.7 \%$ & $22.1 \%$ \\
\hline Currently married & $70.5 \%$ & $61.4 \%$ & $61.8 \%$ & $63.4 \%$ \\
\hline Formerly married & $13.0 \%$ & $22.8 \%$ & $17.5 \%$ & $14.5 \%$ \\
\hline \multicolumn{5}{|l|}{ Age } \\
\hline $20-29$ & $46.2 \%$ & $45.9 \%$ & $47.0 \%$ & $49.8 \%$ \\
\hline $30-39$ & $34.6 \%$ & $31.5 \%$ & $29.7 \%$ & $28.8 \%$ \\
\hline $40-49$ & $19.2 \%$ & $22.6 \%$ & $23.3 \%$ & $21.4 \%$ \\
\hline \multicolumn{5}{|l|}{ Siblings mortality } \\
\hline None & - & $23.5 \%$ & 20.2 & - \\
\hline One or more & - & $76.5 \%$ & 79.8 & - \\
\hline \multicolumn{5}{|l|}{ Migration status } \\
\hline Countryside ، Countryside & - & $74.8 \%$ & $76.0 \%$ & - \\
\hline Countryside ‘ Small City & - & $0.6 \%$ & $0.5 \%$ & - \\
\hline Countryside $<$ Kigali & - & $0.3 \%$ & $0.4 \%$ & - \\
\hline Small City ، Countryside & - & $6.4 \%$ & $9.6 \%$ & - \\
\hline Small City < Small City & - & $3.4 \%$ & $3.3 \%$ & - \\
\hline Small City ، Kigali & - & $0.3 \%$ & $0.3 \%$ & - \\
\hline Kigali ، Countryside & - & $8.9 \%$ & $6.1 \%$ & - \\
\hline Kigali ، Small City & - & $1.9 \%$ & $1.2 \%$ & - \\
\hline Kigali < Kigali & - & $3.1 \%$ & $2.0 \%$ & - \\
\hline \multicolumn{5}{|l|}{ Husband approves FP } \\
\hline Disapprove & - & $18.3 \%$ & $15.8 \%$ & - \\
\hline Approve & - & $54.0 \%$ & $62.4 \%$ & - \\
\hline Don't know & - & $27.7 \%$ & $21.8 \%$ & - \\
\hline
\end{tabular}




\begin{tabular}{lllll}
\hline Discussion about FP & & & & \\
\hline Never & - & $42.1 \%$ & $30.5 \%$ & - \\
Once or twice & - & $23.2 \%$ & $27.0 \%$ & - \\
More often & - & $34.7 \%$ & $42.5 \%$ & - \\
\hline Valid & 5079 & 7694 & 8726 & 5879 \\
\hline
\end{tabular}

Graph I shows the shifts in family preferences between the years in the form of cumulative percentages of the desired number of children. In 1992 close to $30 \%$ wanted no more than 3 children, $70 \%$ regarded four or less as the ideal and 85 wanted less than six children. In 2000 the ideal number of children was much higher. Less than $20 \%$ wanted to stop at three and $50 \%$ indicated that they wanted more than 4 children, and $30 \%$ even wanted 6 or more. In 2005 the pattern illustrates that the fertility preference of women is close to the one in 1992. The fertility preference in $\mathbf{2 0 0 8}$ is radically different if compared to previous years. Of all women aged 20-49 no less than $60 \%$ state that three children or less is the ideal number and $90 \%$ indicate a maximum of four. This huge shift raises some methodological doubt. The 'sensitizing' campaign of the government of Rwanda after 2005, promoting three children as the ideal family size, might have led to socially desirable responses in the 2008 interim RDHS rather than an expression of a conscious change in the fertility behaviour of women.

Table I gives the descriptive statistics for each year of interview. We expected to observe more women that had lost at least one child in the 2000 set, in particular compared to both 1992 and 2008. We found that infant and child mortality rates were already very high in 1992 and in 2000 and they deviated only marginally from the first Rwanda demographic and health survey. We find much higher numbers of formerly married (widowed or separated) women in 2000 and 2005 than in 1992 and in 2008. The data show that urbanization, which is expected to lead to a smaller number of ideal children over time, is on its way in Rwanda but only at a slow pace. The proportion of respondents in the rural neighbourhoods gradually decreases as people prefer to live in small cities or in the capital as those areas are relatively well equipped in terms of infrastructures and offer more socioeconomic opportunities. The proportion living in small cities increased gradually whereas in Kigali the increase is particularly important in
2000. In general, the educational expansion seems to have increased steadily as the proportion of non educated went from $40.4 \%$ in 1992 to $24 \%$ in 2008 . But a closer look at all types of level of education show that the main changes appear in 2000 where the proportions of women with primary and secondary level education have more than doubled. This might be an effect of the return of large numbers of Rwandese living in exile in Burundi, Uganda and Congo before the regime change in 1994. Efforts to stimulate enrolment in primary education have been a major priority of the new administration and could account for the rising levels of (completed) primary education after 2000.

Unfortunately we do not have data on the attitudes on family planning for 1992 and 2008, but the data show the low level of approval in 2000. Only $54 \%$ of the women indicate that their husbands approve family planning and more than $40 \%$ has never discussed it. Five years later approval rates have gone up to $62 \%$ and $70 \%$ has discussed family planning at least once.

The outcomes from the location-scale models in Table 2 and 3 come from two stepwise analyses. The first analysis (Table 2 and Model 3 ) is a general model that tests the assumptions from Demographic Transition Theory. All mechanisms defined in that theory show up with the correct sign. The year of interview, the mortality experience (death of own children), the level of education, the place of residence, the marital status and the respondent's age are all related to the ideal number of children. The mortality experience, the age of respondent and place of residence (with Kigali as reference category) are clearly positively related to large family size preference. Women who experienced many deaths of their children are more likely to desire a large family than the one who lost fewer or did not lose any child. Women aged 30 and over are more likely to prefer a large family than their younger sisters, and living outside Kigali increases the likelihood of preferring a large number of children. 
Table 2 Risk factors of large family size preference (1992 - 2008)

\begin{tabular}{|c|c|c|c|c|c|c|}
\hline \multirow[t]{2}{*}{ Parameter } & \multicolumn{2}{|c|}{ Model I } & \multicolumn{2}{|c|}{ Model 2} & \multicolumn{2}{|c|}{ Model 3} \\
\hline & Location & Scale & Location & Scale & Location & Scale \\
\hline Threshold [0 - 3] & $-0.800 * * *$ & & $-0.423 * * *$ & & -0.265 **** & \\
\hline Threshold [4] & I.122**** & & $1.608 * * * *$ & & $1.682 * * * *$ & \\
\hline Threshold [5] & I.988*** & & 2.517 ***** & & $2.549 * * * *$ & \\
\hline Year [1992] & $0^{\mathrm{a}}$ & $0^{\mathrm{a}}$ & $0^{\mathrm{a}}$ & $0^{\mathrm{a}}$ & $0^{\mathrm{a}}$ & $0^{\mathrm{a}}$ \\
\hline Year [2000] & $0.702^{* * * *}$ & $0.053 *$ & $0.853^{* * * *}$ & 0.042 & $0.824 * * *$ & 0.036 \\
\hline Year [2005] & $0.223^{* * * *}$ & 0.035 & $0.25 I^{* * * * *}$ & 0.039 & $0.254^{* * * *}$ & 0.041 \\
\hline Year [2008] & $-1.420 * * *$ & 0.049 & $-1.499 * * *$ & $0.142 * * *$ & $-1.430 * * *$ & $0.140 * * *$ \\
\hline Child mortality [None] & $0^{\mathrm{a}}$ & $0^{\mathrm{a}}$ & $0^{\mathrm{a}}$ & $0^{\mathrm{a}}$ & $0^{\mathrm{a}}$ & $0^{\mathrm{a}}$ \\
\hline Child mortality [I-2] & $0.288 * * *$ & -0.018 & $0.139 * * *$ & -0.002 & $0.100 * * *$ & 0.007 \\
\hline Child mortality $[3+]$ & $0.366 * * *$ & 0.020 & $0.156 * * *$ & 0.038 & $0.119 * *$ & 0.066 \\
\hline Age [20 - 29] & $0^{\mathrm{a}}$ & $0^{\mathrm{a}}$ & $0^{\mathrm{a}}$ & $0^{\mathrm{a}}$ & $0^{\mathrm{a}}$ & $0^{\mathrm{a}}$ \\
\hline Age [30 - 39] & $0.362^{* * * *}$ & $0.125^{* * * *}$ & $0.312 * * *$ & $0.14 I^{* * * *}$ & $0.264 * * *$ & $0.149 * * *$ \\
\hline Age [40 - 49] & $0.356 * * *$ & $0.101 * *$ & $0.292 * * *$ & $0.129 * * *$ & $0.277 * * * *$ & $0.153 * * *$ \\
\hline$[2000] *[20-29]$ & $0^{\mathrm{a}}$ & $0^{\mathrm{a}}$ & $0^{\mathrm{a}}$ & $0^{\mathrm{a}}$ & $0^{\mathrm{a}}$ & $0^{\mathrm{a}}$ \\
\hline$[2000] *[30-39]$ & $-0.150 *$ & -0.040 & -0.133 & -0.018 & -0.077 & -0.023 \\
\hline$[2000] *[40-49]$ & 0.071 & $0.145^{* *}$ & 0.041 & $0.161 * * *$ & 0.120 & 0.149 \\
\hline$[2005] *$ [20-29] & $0^{\mathrm{a}}$ & $0^{\mathrm{a}}$ & $0^{\mathrm{a}}$ & $0^{\mathrm{a}}$ & $0^{\mathrm{a}}$ & $0^{\mathrm{a}}$ \\
\hline$[2005] *[30-39]$ & $-0.166 * *$ & $-0.118^{* *}$ & -0.092 & $-0.102 * \frac{1}{2}$ & -0.073 & $-0.117^{* *}$ \\
\hline$[2005] *[40-49]$ & 0.007 & 0.011 & 0.062 & -0.005 & 0.109 & -0.028 \\
\hline$[2008] *[20-29]$ & $0^{\mathrm{a}}$ & $0^{\mathrm{a}}$ & $0^{\mathrm{a}}$ & $0^{\mathrm{a}}$ & $0^{\mathrm{a}}$ & $0^{\mathrm{a}}$ \\
\hline$[2008] *[30-39]$ & $0.275^{* * * *}$ & -0.002 & $0.422^{* * * *}$ & -0.036 & -0.073 & $-0.117^{* *}$ \\
\hline$[2008] *[40-49]$ & $0.502^{* * * *}$ & 0.098 & $0.607 * * *$ & 0.072 & 0.109 & -0.028 \\
\hline [None + Inc. Primary] & & & $0^{\mathrm{a}}$ & $0^{\mathrm{a}}$ & $0^{\mathrm{a}}$ & $0^{\mathrm{a}}$ \\
\hline [Primary] & & & $-0.292 * * *$ & $-0.067^{* * * *}$ & $-0.282^{* * * *}$ & $-0.065 * * *$ \\
\hline [Inc. Secondary] & & & $-0.693 * * *$ & $-0.106^{* * * *}$ & $-0.659 * * *$ & $-0.109 * * *$ \\
\hline$[$ Secondary +] & & & $-1.260 * * *$ & 0.033 & $-1.213 * * *$ & -0.029 \\
\hline Kigali & & & $0^{\mathrm{a}}$ & & $0^{\mathrm{a}}$ & \\
\hline Small city & & & $0.35 I^{* * * * *}$ & & $0.334 * * *$ & \\
\hline Countryside & & & $0.740 * * * *$ & & $0.673 * * *$ & \\
\hline Never married & & & & & $0^{\mathrm{a}}$ & $0^{\mathrm{a}}$ \\
\hline Currently married & & & & & $0.309 * * *$ & $-0.077^{* * * *}$ \\
\hline Formerly married & & & & & $-0.190 * * *$ & -0.040 \\
\hline Valid cases & 27379 & & 27379 & & 27379 & \\
\hline
\end{tabular}

Lastly, taking into consideration the marital status, the category of women "currently married" shows log odds ratios of 0.309 and the category of "formerly married" women is negatively deviating $(-0.190)$ from the reference category ("Never married") in terms of ideal number of children. The culture and the policy in Rwanda are not in favour of extramarital births and remarriage for widowed or separated women. It is a phenomenon which is affected by a very low social acceptance. Formerly married women might therefore equate their ideal number to their actual number of children.

Model 6 differs from Model 3 in two aspects. The first is that 1992 and 2008 data-sets were excluded as information on mortality of siblings as well as family planning approval and its discussion by the couple were not included. The second is that Model 6 includes a variable that reflects the migration history combining the current and the childhood place of residence and the year of interview and age of respondents 
have been combined into one variable.

Table 3 Risk factors of large family size preference (2000 - 2005)

\begin{tabular}{|c|c|c|c|c|c|c|}
\hline \multirow[t]{2}{*}{ 2000ñ2005 Parameter } & \multicolumn{2}{|c|}{ Model 4} & \multicolumn{2}{|c|}{ Model 5} & \multicolumn{2}{|c|}{ Model 6} \\
\hline & Location & Scale & Location & Scale & Location & Scale \\
\hline Threshold [0 - 3] & $-1.459 * * *$ & & $-1.894 * * *$ & & $-2.272 * * * *$ & \\
\hline Threshold [4] & $0.332 * * * *$ & & -0.050 & & $-0.506 * * *$ & \\
\hline Threshold [5] & I.134*** & & $0.778 * * * *$ & & $0.315 * * *$ & \\
\hline Year [2000] & $0^{\mathrm{a}}$ & $0^{\mathrm{a}}$ & $0^{\mathrm{a}}$ & $0^{\mathrm{a}}$ & $0^{\mathrm{a}}$ & $0^{\mathrm{a}}$ \\
\hline Year [2005] & $-0.442 * * *$ & $-0.012 * * *$ & $-0.55 \mid$ I*** & -0.008 & $-0.528 * * * *$ & $0.078 * *$ \\
\hline Child mortality [None] & $0^{\mathrm{a}}$ & $0^{\mathrm{a}}$ & $0^{\mathrm{a}}$ & $0^{\mathrm{a}}$ & $0^{a}$ & \\
\hline Child mortality [I-2] & $0.254^{* * * *}$ & -0.021 & $0.093 * * * *$ & -0.005 & 0.054 & \\
\hline Child mortality $[3+]$ & $0.328 * * * *$ & 0.015 & 0.100 & 0.026 & $-0.142 * *$ & \\
\hline Siblingsí mortality [None] & $0^{\mathrm{a}}$ & $0^{\mathrm{a}}$ & $0^{\mathrm{a}}$ & $0^{\mathrm{a}}$ & $0^{\mathrm{a}}$ & $0^{\mathrm{a}}$ \\
\hline$[1-2]$ & $-0.143^{* * * *}$ & $-0.07 \mid * * *$ & $-0.095 * * * *$ & $-0.058 * * *$ & $-0.096 * * * *$ & $-0.049 *$ \\
\hline$[3+]$ & $-0.345 * * *$ & $-0.06 I^{*}$ & $-0.150 * * *$ & -0.054 & $-0.123 *$ & 0.001 \\
\hline Age [20 - 29] & $0^{\mathrm{a}}$ & $0^{\mathrm{a}}$ & $0^{\mathrm{a}}$ & $0^{\mathrm{a}}$ & $0^{\mathrm{a}}$ & $0^{\mathrm{a}}$ \\
\hline Age [30 - 39] & $0.212 * * *$ & $0.091 * * *$ & $0.179 * * *$ & $0.120 * * *$ & $0.286 * * *$ & $0.202 * * *$ \\
\hline Age [40 - 49] & $0.418 * * *$ & $0.252 * * *$ & $0.325 * * *$ & $0.289 * * *$ & $0.364 * * *$ & $0.389 * * *$ \\
\hline$[2005] *[20-29]$ & $0^{\mathrm{a}}$ & $0^{\mathrm{a}}$ & $0^{\mathrm{a}}$ & $0^{\mathrm{a}}$ & $0^{\mathrm{a}}$ & $0^{\mathrm{a}}$ \\
\hline$[2005] *[30-39]$ & -0.016 & $-0.085^{* *}$ & 0.034 & $-0.075^{*}$ & 0.045 & $-0.186 * * *$ \\
\hline$[2005] *[40-49]$ & -0.054 & $-0.158 * * *$ & 0.023 & $-0.164 * * *$ & 0.075 & $-0.277^{* * * *}$ \\
\hline [None + Inc. Primary] & & & $0^{\mathrm{a}}$ & $0^{\mathrm{a}}$ & $0^{\mathrm{a}}$ & $0^{\mathrm{a}}$ \\
\hline [Primary] & & & $-0.296 * * * *$ & $-0.082 * * *$ & $-0.300 * * * *$ & $-0.055^{*}$ \\
\hline [Inc. Secondary +] & & & $-0.615 * * * *$ & $-0.145^{* * * *}$ & $-0.494 * * *$ & $-0.154 * * * *$ \\
\hline$[$ Secondary +$]$ & & & $-1.197 * * *$ & $-0.098^{*}$ & $-1.132 * * *$ & 0.047 \\
\hline [Countryside - Countryside] & & & $0^{\mathrm{a}}$ & $0^{\mathrm{a}}$ & $0^{\mathrm{a}}$ & $0^{\mathrm{a}}$ \\
\hline [Countryside -Small city] & & & -0.093 & 0.164 & -0.093 & $0.312 *$ \\
\hline [Countryside - Kigali] & & & $-0.375 * *$ & $-0.339 * *$ & $-0.479 * *$ & $-0.351 * *$ \\
\hline [Small city - Countryside] & & & $-0.33 \mid$ I*** & $-0.124 * * * *$ & $-0.272 * * * *$ & $-0.104 * *$ \\
\hline [Small city - Small city] & & & $-0.444 * * *$ & 0.000 & $-0.230 *$ & $0.138^{*}$ \\
\hline [Small city - Kigali] & & & $-0.658 * * *$ & -0.137 & $-0.484 * *$ & -0.193 \\
\hline [Kigali - Countryside] & & & $-0.7 \mid I * * * *$ & $-0.080 * *$ & $-0.739 * * *$ & -0.070 \\
\hline [Kigali - Small city] & & & $-0.474 * * *$ & 0.017 & $-0.516 * * * *$ & 0.085 \\
\hline [Kigali - Kigali] & & & $-0.923 * * *$ & -0.050 & $-0.774 * * *$ & -0.001 \\
\hline Partner [Disapproves] & & & & & $0^{\mathrm{a}}$ & $0^{\mathrm{a}}$ \\
\hline Partner [Approves] & & & & & $-0.353^{* * * *}$ & $-0.194 * * *$ \\
\hline [Don't know] & & & & & -0.086 & -0.057 \\
\hline Discuss FP [Never] & & & & & $0^{\mathrm{a}}$ & $0^{\mathrm{a}}$ \\
\hline Discuss FP [Once or twice] & & & & & -0.054 & 0.006 \\
\hline Discuss FP [More often] & & & & & $-0.254 * * *$ & $-0.083 * *$ \\
\hline Valid cases & 16420 & & 16352 & & 9918 & \\
\hline
\end{tabular}

The period 2000 and 2005 is close to the period of the genocide and could therefore give a better image of the short-term impact of that disruptive event on fertility preference. Although the offspring mortality appears to be positively
(0.254 to 0.328$)$ related to family size preferences, this relationship progressively loses its significance when including variables related to modernisation progress and even becomes negative when attitudes of the partner enter the 
model.

We hypothesized that the loss of siblings would also lead to a higher desired number of children. The death of siblings shows a limited and negative significant relationship with the preference for a large family. This means that women who lost their siblings due to the civil war and the genocide do not particularly desire a high number of children. As expected there is a negative association between partners who approve or discuss family planning as well as the education level along with the ideal family size.

Again as expected the age of respondents is positively related with the fertility preference, meaning that younger women are less likely to prefer large family sizes than their elder sisters. As in the previous model with the four data sets (Table 2) we that found that the women aged 30-39 and 40-49 are not homogeneous in terms of the ideal number of children as the scale model shows clear positive and significant estimates. Again, this could mean that these age groups consist both of people that have been witness to the genocide and of people that returned to the country afterwards. Unfortunately the data does not allow a classification of people that left the country previously and returned after the period of atrocities, but we can reconstruct a variable showing whether people remained in the countryside, moved to a small city or to the capital Kigali, testing the hypothesis that urbanization corresponds to a desire for smaller families.

The migration history does have the expected effect. In particular people moving to Kigali from the countryside show lower numbers of desired children (-0.739), compared to those that stayed. The smaller cities are indeed somewhere in between, but people who moved to these places from Kigali clearly want fewer children (-0.484). Again, as expected, women who live in Kigali and did not move since their childhood have the lowest estimates of preference for large family size $(-0.774)$.

Model 6 pertains to currently married women which enables the inclusion of the husband approval of family planning and discussion with partner about the family planning. Even though Rwanda is not a very strict patriarchal society we did expect a substantial influence of the husband attitudes towards reproductive health on the desired number of children as reported by women. The parameters are in line with this hypothesis and indicate a significant effect $(-0.353)$ if both approve of family planning and if partners discuss it as a couple $(-0.254)$. Women who declared that they had a discussion about family planning with their partner only once or twice are not significantly different from those who had never discussed the matter.

Even after controlling for mortality experience and other risk factors, the year 2000 stands out as the year in which ideal family size is higher. Although this might be the result of unobserved heterogeneity, it could mean that the mindset in general is more in favour of more children after a disruptive event.

\section{Discussions and conclusion}

The relevant fact is that preference for a large family size is very high in 2000 compared to all other years regardless of the level of mortality experience. The variable year of interview shows a very high increase in the preference for large families in the year 2000 and a very steady drop in the years after. The loss of explanatory power of the mortality experience after inclusion of education and urbanisation variables indicates that its role maybe different in exceptional circumstances.

As stated in the methodology section, the scale model offers the opportunity to address the issue of heterogeneity in the ideal number of children within groups of women. On the whole most scale effects are either not significant or small, with the exception of the parameters for the year 2008 and the higher age groups. As these parameters are positive it means that heterogeneous responses are more common in 2008 , indicating that here might be minority groups that still favour large families. The dispersion in the higher age groups might indicate unobserved heterogeneity between cohorts that might be linked to experience of the genocide not captured by the actual loss of children. The scale parameter is in particular substantial for the highest age group in 2000.

This paper aims to contribute to the debate on the stalling fertility decline in sub-Saharan Africa, by analyzing the role of disruptive events in shaping the fertility preferences in Rwanda using the Rwanda DHS datasets from 1992 to 2008. 
We are not measuring ideal family size as a proximate determinant of actual fertility but as a general opinion as to how many children would be appropriate to women in Rwanda either prospectively for young women or retrospectively for their elder sisters. This relative definition emphasizes the orientation of this study to whether the fertility preference may have been affected by the civil war and genocide in Rwanda.

This paper captures three mechanisms through which disruptive events may account for the change in the fertility preference level. The first mechanism is the mortality experience, the direct consequence of major crises. The proxies used in this study to capture the mortality experience that is expected to lead to desire a large family were the mortality of offspring and the mortality of respondents' siblings. The second mechanism refers to common trends like further educational expansion and rapid urbanization, which are known to lead to desires for smaller families and are generally interrupted as a result of major crises. The third mechanism expands our views to the attitudinal variables of third parties that may account for the change of fertility preferences after a disruptive event. These variables are a husband's approval of family planning and its discussion by the couple.

Using data from four consecutive Demographic and Health Surveys we were able to show for Rwanda over a period of sixteen years that infant and child mortality remained at a high level, with only slight improvements after 2005. Educational expansion slowed down in this period. Urbanization progressed at a relatively slow but steady pace during this period.

The multivariate analyses indeed corroborate the existing insights that these factors play a decisive role in the desired family size, and part of the stall in the fertility decline can therefore be related to the fact that the determinants of fertility preferences hardly changed over time. The expected influence of mortality experience on the fertility preference related to the insurance hypothesis was not found to be as important as the modernization process. The migration status stresses the facts that living or having lived in Kigali contributes a lot to a desire for smaller families; furthermore, the level of education has a strong effect on the desired family size. Young generations are less likely to prefer large families. The approval or the discussion of family planning by the couple is also contributing significantly to lower fertility preference.

The scale model does show that the highest age groups in particular are heterogeneous in their fertility preferences in 2000 . We speculated that this might be linked to their country of residence during the genocide. Many people returned from exile after the end of the civil war and this might account for the heterogeneity within this group. Unfortunately the data do not allow us to bring this distinction into our models. Even after controlling for the factors that contribute to the explanation of the ideal family size, the year 2000 and to a lesser extent 2005 stand out in having exceptional high levels of desired fertility. This provides some evidence that violent deaths change the overall mind-set of the population to more pro-natalist attitudes. A more in-depth analysis of the effects of children's mortality showed that these are indeed stronger in the aftermath of the genocide in Rwanda. However, we found no support for the idea that the loss of siblings also contributes to the explanation of wanting more children.

It is clearly seen that fertility decline may resume in the years to come. Further educational expansion and urbanization and decreasing levels of infant and child mortality will certainly lower the desired number of children. Also the mind-set seems to have shifted, considering the huge shift in the reported ideal family size in 2008. This might be result of the 'sensitizing' campaign by the Rwandan government, which could have led respondents in the questionnaire to include "what is good for the country" in their response to the question on the personal ideal with respect to the number of children. However, a decrease in ideal family size alone is not enough to bring down actual fertility. Access to reproductive services is a requisite to arriving at the ideal family size.

\section{Acknowledgements}

We thank participants in the Sixth African Conference on African Population: Past, Present and Future (Ouagadougou, December 20ll) for their useful suggestions and comments. The findings, interpretations, and conclusions expressed in this paper are entirely those of the authors. 


\section{References}

Bankole, A. and Westoff, C.F. 1998. The Consistency and Predictive Validity of Reproductive Attitudes: Evidence from Morocco. Journal of Biosocial Science Vol.30(4): 439-455.

Bongaarts, J. 2006. The Causes of Stalling Fertility Transitions. Studies in Family Planning Vol.37(I): I16

Cochrane, S.H., Khan, M.A., and Osheba, I.K.T., 1990. Education, Income and Desired Fertility in Egypt: A Revised Perspective. Economic Development and Cultural Change Vol.38(2): 3I3319.

De Silva, W.I. 199I. Consistency between Reproductive Preferences and Behavior: The Sri Lankan Experience. Studies Family Planning Vol. 22(3): 187-199.

Ezeh, A.C. 1993. The Influence of Spouses over Each Other's Contraceptive Attitudes in Ghana. Studies in Family Planning Vol. 24(3): 163-I 74.

Garenne M. and Gakusi E. 2005. Under Five Mortality Trends in Africa: Reconstruction from Demographic Sample Surveys. DHS Working Paper Series, No26.

Goni, A. and Saito, O. 2009. Fertility Decline and Women's Status- The Role of non-Government Organisations in Bangladesh: A micro-data analysis. International NGO Journal Vol. 5(4): 88100.

Janowitz, B.S. 1976. An Analysis of the Impact of Education on Family Size. Demography Vol. I3(2): 189-198.

Jejeebhoy, S.J. 1995. Women's Education, Autonomy, and Reproductive Behaviour: Experience from Developing Countries. Clarendon Press, New York, 306 p.

Knodel, J.E., Ruffolo V.P., Ratanalangkarn, P., and Wongboonsin, K. (1996). Reproductive Preference in Post-transition Thailand: Implication for the Future Course of Fertility. Studies Family Planning Vol. 24(6): 307-3 8.

Kulu, H. 2005. Migration and Fertility: Competing Hypothesis Re-examined. European Journal of Population Vol.2I(I): 5I-87.

Lall, R., Campbell, et al. 2002. A Review of Ordinal Regression Models Applied on Health-related Quality of Life Assessments. Statistical Methods in Medical Research Vol. II: 49-67.

LeGrand, T.K. et al. 2003. Reassessing the Insurance Effect: A Qualitative Analysis of Fertility Behavior in Senegal and Zimbabwe. Population and Development Review Vol. 29(3): 375-403.

Lindstrom, D.P. and Berhanu, B. 1999. The Impact of War, Famine, and Economic Decline on Marital Fertility in Ethiopia. Demography, Vol.36(2): 247-
261.

McCarthy, J. and Oni, G.A. 1987. Desired Family Size and Its Determinants Among Urban Nigerian Women: A Two Stage Analysis. Demography, Vol. 24, 2, pp.279-290.

Republic of Rwanda, Ministry of Finance and Economic Planning, 2003. Third General Census of Population and Housing of Rwanda (2002), National Census Service, Kigali, Rwanda.

Nobles, J. and Buttenheim, A. 2006. Marriage in Period of Crisis: Evidence from Indonesia. California Center for Population Research, UCLA, WP CCPR-0I7-06.

Norris, C.M., et al., 2006. Ordinal Regression Model and the Linear Regression Model were Superior to the Logistic Regression Models. Journal of Clinical Epidemiology Vol. 59(5): 448-456.

Pullum, T.W. 1983. Correlates of in Family Size Desires, In Bulatao, R.A. and Lee, R.D. (eds) Determinants of Fertility in Developing Countries, New York: Academic Press: pp. 278-298.

Schindler K. and Brück T. 20I I. The Effects of Conflict on Fertility in Rwanda. World Bank. Poverty Reduction and Economic Management Network. Gender and Development Unit. WPS No57I5.

Schoumaker, B., 2008. Stalls in Fertility Transitions in sub-Saharan Africa: Real or Spurious? Centre de Recherche en Démographie et Sociétés, UCL, Document de Travail No 30.

Scott, S.C., et al., 1997. Statistical Assessment of Ordinal Outcomes in Comparatives Studies. Journal of Clinical Epidemiology Vol.50(I): 45-55.

Shapiro, T. and Gebreselassie, T. 2008. Fertility Transition in sub-Saharan Africa: Falling and Stalling. African Population Studies, Vol.22(2)/ Vol.23(I).

Steenkamp, J-B.E.M, et al. 2010. Socially Desirable Response Tendencies in Survey Research. Journal of Marketing Research, Vol. XLVII: 199-2I4.

Uche, C. and Isugo-Abanihe, 1994. Reproductive Motivation and Family Size Preferences among Nigerian Men. Studies in Family Planning, Vol. 24, pp. I49-16I.

Verwimp P. and de Walque D., 20I0. "The Demographic and Socio-economic Distribution of Excess Mortality during the 1994 Genocide in Rwanda," Journal of African Economies, Oxford University Press, vol. 19(2), pages I4I-I62.

Williams, R., 2009. Using Heterogeneous Choice Models To Compare Logit and Probit Coefficients Across Groups. Sociological Methods and Research, Volume 37(4):53I-559.

Woldemicael, G., 2007. Women's Status and Reproductive Preferences in Eritrea. MPIDR, Working Paper, WP 2007-023, 27p. 